253 ; 1981) "guaranteed that sudden rupture of the pipes could not occur" and, as a measure of last resort, the incorporation of an automatic emergency water cooling system. This was designed to cope with the worst possible case foreseen, the transverse fracture of a $900-\mathrm{mm}$ turbine pressure collector. On 26 April, however, this system clearly failed to work.

If the Soviet atomic energy commission preserves the reticence it has shown so far, it may be difficult to discover not only what caused the initial fault but also why the emergency system failed to operate. (Earlier this year, the daily Sovetskaya Rossiya called for greater openness in the reporting of natural disasters, but the atomic energy commission could well reply that the Chernobyl accident was not "natural".) One possible explanation, however, may lie in Soviet construction procedures which are prone to produce shoddy and hazardous results, in spite of the fact that there is no "capitalist" profit motive.

The Soviet practice of laying down quarterly, annual and five-year production targets (with pay and bonuses dependent on their fulfilment), coupled with a highly bureaucratic supply system and a transport network too overloaded to ensure prompt deliveries, has led to the practice of "storming" - last-minute speed-ups and overtime to catch the target date.

Hasty construction is further exacerbated by the emphasis placed on fulfilling targets ahead of plan, and, in particular, the making of "voluntary" pledges by the workers to reduce their target time in honour of major patriotic events. Although, in 1976, a glowing description of the construction work at the Chernobyl site merited front-page treatment in Pravda, an article that appeared in the weekly Literaturna Ukrayina just a month before the accident gave a very different picture.

According to the author, Lyubov Kovalevs'ka from the town of Prypyat', building standards have from the very beginning been neglected. The construction of a project such as a nuclear power station, she says, must be "a continuous flow on the basis of the strictest adherence to building technology. But this did not happen here."

The various problems that arose with the first unit (Kovalevs'ka does not specify what they were) were never properly solved, but simply "transferred" to the second, and then to the third and fourth units.

What this meant in practice is seen from her description of current construction work on the fifth unit. The project, she says, is beset by constant shortages; materials are delivered in inadequate quantities and are frequently substandard, yet the planned construction

time has been cut from three years to two. The workforce therefore has no option but to try to fulfil its targets by neglecting the specifications and "stretching" such materials as there are as far as possible, and accepting defective supplies even when so vital an item is concerned as the

\title{
Nuclear prognostications
}

\section{Estimating gravity of problem}

Although several agencies in the West have been hard at work during the past week trying to estimate the seriousness of the accident at the Soviet nuclear reactor north of Kiev, nobody is confident of the outcome of their calculations. As part of the now-standard process of calculating the consequences of hypothetical nuclear accidents, several computer models have been developed for estimating what happens to radioactivity released from a damaged reactor. But, as one modeller explained last week, "usually we start with something that we know".

Part of the problem is meteorological. One of the team at the British Radiological Protection Board, an independent government agency based at Harwell, Oxfordshire, explained last week that there is relatively little experience of even models of the spread of radioactive materials from sources remaining active for several days, and that the calculation of the consequences of Chernobyl have been complicated by the rapidly changing wind patterns.

Data from Sweden and elsewhere in Europe have thrown some light on the composition of the fallout from the Soviet reactor. It seems to be agreed that the concentrations of volatile materials such as radioactive iodine and caesium are in the proportions to be expected from fresh fission products. The modellers are, however, unable to estimate with any certainty what proportion of the total emission from the damaged plant will have been deposited in its immediate locality.

This uncertainty bears most directly on the difficulty of estimating the damage that may have been done to the population in the immediate vicinity of the plant, which will become apparent there only in the next few days and even weeks. One of those concerned says the uncertainties are such that the data from outside the Soviet Union are consistent both with the assumption that many people will have been exposed to damaging doses of radiation and that there will be no casualties from radiation sickness even in the neighbourhood of the plant.

There is, however, general scepticism about some of the estimates of Soviet casualties such as that given to a congressional committee by Dr Kenneth Adelman. director of the US Arms Control and Dis- case she cites, the roof-plate for the spent fuel bunker. Quality and inspection of the finished construction moreover, seems to connive at the situation which. Kovalevs'ka warned a month ago, will have to be "paid for over the course of decades". Has this bill yet been paid? Vera Rich

armament Agency. It is pointed out that calculations of the consequences of releases of radioactivity from pressurized water reactors, such as the estimates prepared for the public inquiry into the British plan to build such a plant at Sizewell in Suffolk, suggest that acute deaths (within a few weeks) would be counted in hundreds, not thousands. The longerterm consequences - excess cancer deaths - would usually be greater in number.

The generalized effects of the radioactivity observed in Sweden will be much smaller. If atmospheric radioactivity was last week six times greater than the natural background for two or three days, the result will be increased exposure to radiation by a few per cent of the annual dose arising naturally. But this reassuring yardstick does not exclude the possibility that some people may ingest exceptional amounts of artificial radioactivity by the accumulation and concentration of particular radionuclides in foodstuffs.

Attempts to estimate the total amount of radioactivity released at Chernobyl are similarly uncertain. The source of the estimate that a total of $10^{\text {is }}$ bequerel were released at Chernobyl was most of all anxious that the uncertainties, which must be several orders of magnitude, should be clearly appreciated. By this yardstick. the Chernobyl accident may be 100 times potentially more damaging than that at Windscale in 1957, when an air-cooled graphite reactor caught fire. That accident was in turn much more serious, as measured by the total quantity of radioactivity released, than the accident at Three Mile Island eight years ago.

Among those with military and arms control interests, some importance is attached to the likelihood that reactors of the "Leningrad" type such as those at Chernobyl would have been a useful source of military plutonium.

According to the International Atomic Energy Agency's survey of the world's reactors published at the end of last year. there were 26 light-water-cooled graphitemoderated reactors in operation in the Soviet Union at the end of 1984 , producing between them a total of $13.7 \mathrm{GW}$ of electricity. A further nine reactors of this type were being built at that stage, although the bulk of the reactors now under construction in the Sovict Union are pressurized-water reactors. 